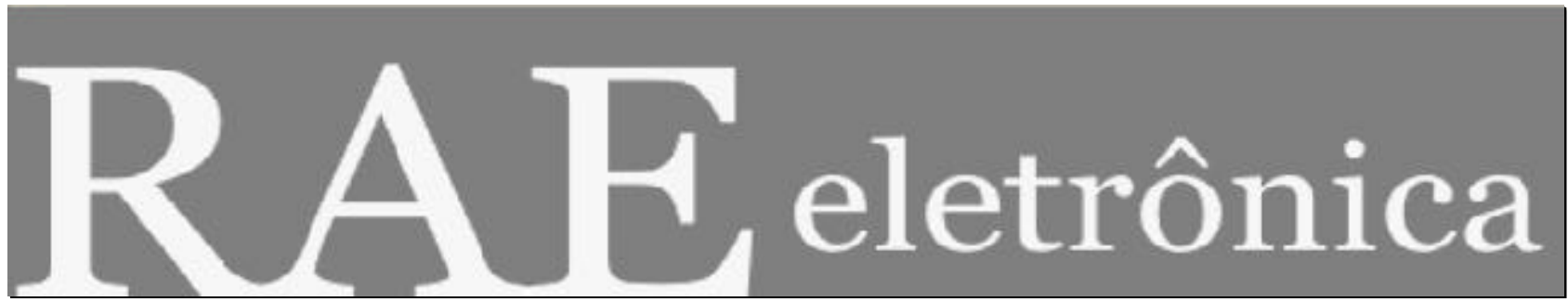

\title{
PROPOSTA DE UM MODELO ESTRUTURADO DE ANÁLISE DE DEMONSTRAÇÕES CONTÁBEIS
}

Por:

\section{Ariovaldo dos Santos \\ Silvia Pereira de Castro Casa Nova}

RAE-eletrônica, v. 4, n. 1, Art. 8, jan./jul. 2005

http://www.rae.com.br/eletronica/index.cfm?FuseAction=Artigo \&ID=2176\&Secao=ARTIGOS\&Volu $\mathrm{me}=4 \&$ Numero $=1 \& \mathrm{Ano}=2005$

CCopyright, 2005, RAE-eletrônica. Todos os direitos, inclusive de tradução, são reservados. É permitido citar parte de artigos sem autorização prévia desde que seja identificada a fonte. A reprodução total de artigos é proibida. Os artigos só devem ser usados para uso pessoal e nãocomercial. Em caso de dúvidas, consulte a redação: raeredacao@fgvsp.br.

A RAE-eletrônica é a revista on-line da FGV-EAESP, totalmente aberta e criada com o objetivo de agilizar a veiculação de trabalhos inéditos. Lançada em janeiro de 2002, com perfil acadêmico, é dedicada a professores, pesquisadores e estudantes. Para mais informações consulte o site www.rae.com.br/eletronica.

\section{RAE-eletrônica}

ISSN 1676-5648

(C2005 Fundação Getulio Vargas - Escola de Administração de Empresas de São Paulo.

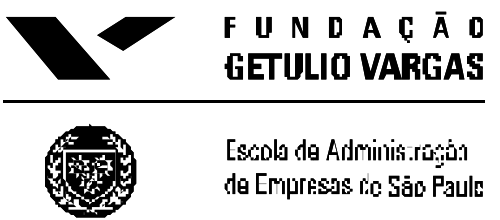




\title{
RESUMO
}

Este estudo apresenta um modelo estruturado de análise de demonstrações contábeis, baseado em Análise por Envoltória de Dados. Embora bastante difundida no exterior, com mais de 400 trabalhos publicados entre 1978 a 1992 (Charnes, Cooper, Lewin \& Seiford, 1997: 11), poucos estudos trataram da utilização da DEA em análise de demonstrações contábeis. Para tanto foi desenvolvida uma metodologia que relaciona etapas e procedimentos para estruturação de um modelo DEA partindo-se das informações contidas em demonstrações contábeis de empresas do setor elétrico brasileiro, obtidas da base de dados Melhores e Maiores de Fipecafi-Exame, para os anos de 1999 e 2000. Os escores de eficiência obtidos pela aplicação do modelo foram comparados com o indicador de Excelência Empresarial de Melhores e Maiores e com o Retorno sobre o Patrimônio Líquido, indicador contábil tradicional, explorando-se vantagens e limitações. Os resultados preliminares apontaram para a complementaridade dos métodos de avaliação de empresas apresentados. Ressalte-se a recomendação de utilizá-los conjuntamente, explorando as divergências entre os métodos e expandindo a compreensão dos fatores que influenciam a eficiência empresarial.

\section{PALAVRAS-CHAVE}

Análise de demonstrações contábeis, análise por envoltória de dados, avaliação econômica, avaliação de desempenho, contabilidade.

\begin{abstract}
This study presents a structured model for financial statement analysis, based on Data Envelopment Analysis. Although this method is quite disseminated abroad, where more than 400 studies were published between 1978 and 1992 (Charnes, Cooper, Lewin \& Seiford, 1997: 11), there is little research on the use of DEA in financial statement analysis. Thus, we developed a methodology that links up stages and procedures for the structuring of a DEA model, starting from the financial statement information of Brazilian electricity companies for 1999 and 2000, which was obtained from the Fipecafi-Exame database Melhores e Maiores. We compared the efficiency rates achieved by applying the model with the Melhores e Maiores Business Excellency index and with the Return on Net Equity, a traditional financial ratio, and explored their advantages and limitations. The preliminary results point towards the complementariness of the above presented company valuation methods. We recommend that they be used jointly, exploring the divergences between them and, hence, reaching a better understanding of the factors that influence business efficiency.
\end{abstract}

\section{KEYWORDS}

Balance sheet analysis, data envelopment analysis, economic valuation, performance evaluation, accountancy. 


\section{INTRODUÇÃO}

O objetivo desse estudo é apresentar um modelo estruturado de análise de demonstrações contábeis com a utilização da Análise por Envoltória de Dados. Está dividido nas seguintes partes: (1) inicialmente foi traçado um histórico da evolução da análise das demonstrações contábeis; (2) apresentourse, então, uma breve revisão conceitual de Análise por Envoltória de Dados; (3) a seguir foram relacionados os estudos anteriores que reuniram DEA e análise de demonstrações contábeis; (4) o modelo proposto foi de talhado e aplicado a um grupo de empresas do setor elétrico brasileiro; (5) finalmente, os resultados foram analisados, explorando-se principalmente as divergências entre indicadores tradicionais e os escores obtidos pelo modelo proposto.

\section{ASPECTOS CONCEITUAIS}

\section{Evolução da Análise de Demonstrações Contábeis}

As demonstrações contábeis divulgadas pelas empresas têm sido objeto de diversos estudos. Tem-se tentado com as informações contábeis derivar modelos de orientação para investidores e credores, por meio da chamada análise de demonstrações contábeis. Para alguns, mais do que uma técnica a análise de balanços, ou ainda, a análise de demonstrações contábeis, é uma arte. Construíram se indicadores de previsão de insolvência, com base em instrumentos quantitativos sofisticados. São amplamente conhecidos os modelos estatísticos de previsão de insolvência. O pioneiro, segundo Silva (1997: 276), foi o estudo de Fitz Patrick, de 1932, que selecionou aleatoriamente 19 empresas que haviam falido no período de 1920 a 1929, com o objetivo de compará-las com outras 19 empresas bem-sucedidas. Beaver (1967 apud Simak, 1997: 8) fez a primeira análise moderna de indicadores contábeis para previsão de falência. O modelo mais conhecido e citado é o de Altman (1968), o primeiro a utilizar a análise discriminante para determinar uma equação que possibilita avaliar a probabilidade de insolvência de empresas. No Brasil, foi construído por Kanitz, em 1974, o chamado Termômetro de Insolvência, utilizando-se igualmente da análise discriminante. Altman, Baidya e Dias, em 1979, propuseram uma adaptação do modelo Z-Score à previsão de problemas financeiros em empresas brasileiras. Silva, em 1983, discutiu modelos de insolvência no Brasil, segregando-os por região e setor de atuação das e mpresas.

Com base em informações financeiras divulgadas e em questionários respondidos, publicações preparam rankings de desempenho, relacionando empresas segundo critérios estabelecidos. Um dos rankings internacionais mais conhecidos é publicado pela Fortune nos Estados Unidos. No Brasil, entre as publicações pioneiras estão a Conjuntura Econômica, da Fundação Getúlio Vargas, e a Melhores $e$ Maiores, edição especial da revista Exame que conta com supervisão técnica da Fundação Instituto de Pesquisas Contábeis, Atuariais e Financeiras (Fipecafi), conveniada à Faculdade de Economia, Administração e Contabilidade da Universidade de São Paulo (FEA - USP). 
A análise de demonstrações contábeis, uma das formas de avaliação econômica de empresas utilizada pelo usuário externo, tem sido aplicada com três enfoques distintos: análise tradicional, modelos integrados de análise e análise estruturada.

No enfoque tradicional, a análise de demonstrações contábeis é um trabalho artesanal. A avaliação depende muito da capacidade e experiência do analista. É, muitas vezes, não padronizada e aplica-se, sobretudo, a pequeno número de empresas. É uma análise aprofundada que demanda tempo na preparação de informações e na condução das conclusões. É muito utilizada como suporte a decisões de investimentos ou concessões de financiamentos. Aplica-se, igualmente, às pesquisas que pretendam determinar padrões de divulgação, adoção de práticas contábeis ou análises setoriais. Pode, no entanto, ser uma etapa da preparação e padronização de informações para aplicação de modelos estatísticos. É iniciada com a leitura detalhada e minuciosa das demonstrações contábeis, a reclassificação de contas buscando a padronização das práticas contábeis e o cálculo de indicadores e percentuais.

Os modelos integrados de análise de demonstrações contábeis surgem para organizar e condensar a informação, permitindo afastar a subjetividade do analista. O que está na base da compreensão desses modelos é o entendimento do desempenho como fator multidimensional e que somente será possível sua compreensão mediante análise conjunta de indicadores. Os pesquisadores que investiram em seu estudo e desenvolvimento objetivaram identificar quais os fatores determinantes do desempenho econômico, qual a ponderação entre os fatores e como obter uma medida sintética e única, considerando os fatores importantes e sua ponderação. Essas etapas são cumpridas, muitas vezes, com a utilização de métodos quantitativos. Os modelos desenvolvidos utilizaram como ferramentas, entre outras: Teste de hipóteses (Kanitz, 1976); Análise de regressão linear (Valle, 2000); Análise Discriminante (Altman, 1968; Altman, Baidya e Dias, 1979; Elizabetsky, 1976; Kanitz, 1974; Silva, 1982; Silva, 1983).

Propõe-se uma evolução à análise de demonstrações contábeis no presente estudo. É uma construção que tem seus fundamentos em todas as etapas anteriormente percorridas, desde a análise tradicional até os modelos integrados de análise. O modelo proposto, portanto, não prescinde de nenhum dos outros modelos; ao contrário, nutre-se deles. A Figura 1 resume a proposta.

\section{Figura 1 - Evolução da avaliação de desempenho pela análise de demonstrações contábeis}

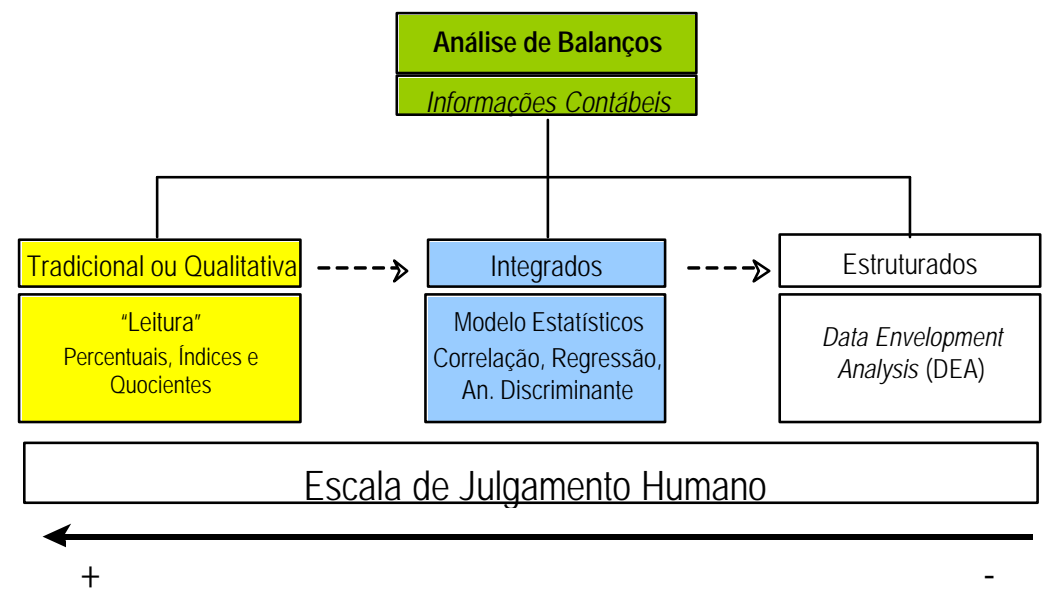


A análise de desempenho caminha assim de um alto grau de envolvimento humano e, portanto, de subjetividade, para uma escala crescente de estruturação. Entende-se por estruturação a determinação de etapas de análises sucessivas, colocadas em uma seqüência lógica, de forma a conduzir o analista às conclusões ou de apontar necessidade de dados adicionais. O modelo é, portanto, retroalimentado, e as etapas se sucedem em ordem progressiva e se repetem, se necessário.

A primeira etapa é uma análise detalhada das informações pela leitura das demonstrações contábeis, de forma a compreendê-las em sua integridade. Na segunda etapa são calculados os índices, percentuais e quocientes tradicionais. Pode-se, então, proceder à utilização de modelos estatísticos. $\mathrm{O}$ tratamento estatístico das informações permite identificar características individuais de cada empresa analisada e confrontá-las com o conjunto de empresas considerado.

A etapa que está sendo acrescentada com a utilização da Análise por Envoltória de Dados alimenta-se das informações das fases anteriores para construir um modelo de avaliação de desempenho que auxilie na determinação da excelência empresarial. Apresenta-se na Figura 2 uma representação esquemática das etapas do Modelo de Análise de Demonstrações Contábeis proposto.

Figura 2 - Etapas propostas para o modelo DEA de análise de demonstrações contábeis

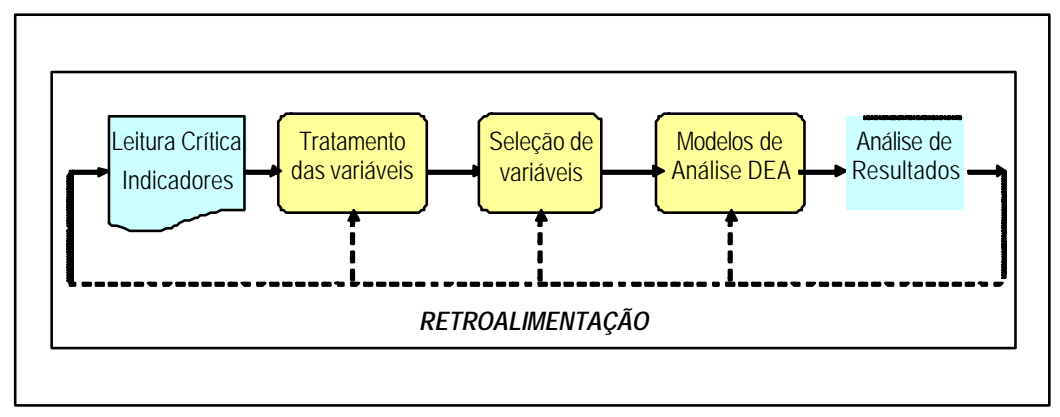

\section{Análise por Envoltória de Dados (DEA)}

O histórico de desenvolvimento do método da Análise por Envoltória de Dados inicia com a tese de doutoramento de Edwardo Rhodes, apresentada à Carnegie Mellon University em 1978, sob a orientação de W. W. Cooper. O estudo resultou na formulação do modelo CCR (abreviatura de Charnes, Cooper e Rhodes, sobrenome de seus autores) de Análise por Envoltória de Dados e com a publicação do primeiro artigo no European Journal of Operations Research em 1978.

A DEA utiliza o método de otimização de programação matemática para, partindo, da medida de eficiência técnica em casos de único produto/insumo proposta por Farrel em 1957, desenvolver um modelo que atenda a casos com múltiplos produtos/insumos, com a construção de um único produto "virtual” e um único insumo "virtual" (Charnes, Cooper, Lewin \& Seiford, 1997: 3).

É aplicável às organizações (referenciadas na literatura como Decision Making Units - DMUs) que sejam caracterizadas por múltiplos insumos e múltiplos produtos. Utiliza, para cada organização, técnicas de programação linear no cálculo de indicador de eficiência que compara seu desempenho com a combinação convexa mais eficiente das outras observações (produto/insumo virtual). $\mathrm{O}$ indicador 
assume o valor de 1 para as DMUs cuja produtividade é "maior" e menos de 1 se combinações alternativas de insumos/produtos são indicadas como mais eficientes (Yunos \& Hawdon, 1997: 258).

A formulação matemática do modelo CCR original pode ser assim apresentada (Ceretta \& Niederauer, 2000: 3): "Considere-se $\mathrm{N}$ empresas produzindo $m$ quantidades de produtos y a partir de $\mathrm{n}$ quantidades de insumos x. Uma empresa $\mathrm{k}$ qualquer produz yrk quantidades de produtos com a utilização de xik quantidades de insumos. O objetivo da DEA é encontrar o máximo indicador de eficiência $\mathrm{h}_{\mathrm{k}}$ onde $\mathrm{u}_{\mathrm{r}}$ é o peso específico a ser encontrado para um produto $\mathrm{r} e \mathrm{v}_{\mathrm{i}}$ o peso específico de cada insumo i."

$\operatorname{Maximizarh}_{k}=\sum_{r=1}^{s} u_{r} y_{r k}$

sujeito a

$\sum_{r=1}^{m} u_{r} y_{r j}-\sum_{i=1}^{n} v_{i} x_{i j} \leq 0$

$\sum_{i=1}^{n} v_{i} x_{i k}=1$

$u_{r}, v_{i} \geq 0$

$h_{k}=$ indicador de eficiência para a empresa $k$

$y_{r j}=$ quantidadedo produto r produzida pela empresa $j$

$x_{i j}=$ quantidadedo insumo iconsumida pela empresa $j$

$y=$ quantidadede produtos $; x=$ quantidadedeinsumos $; u, v=$ pesos

$r=$ número de produtos $=1, \ldots, m ; i=$ número deinsumos $=1, \ldots, n$

$j=$ númerode empresas $=1, \ldots, N$

Assim, tendo-se um conjunto de empresas e seu plano de produção realizado pode-se construir uma curva de produção que se constitui, então, no conjunto de produção revelado. Resolvendo-se o problema de programação linear proposto para cada uma das empresas, pode-se identificar aquelas cujo plano de produção, dados os pesos determinados para suas quantidades de produtos e insumos, não pode ser superado pelo plano de nenhuma outra empresa. A empresa é dita eficiente e torna-se referência para as demais. Resolvendo-se sucessivamente o problema para todas as empresas que compõem o conjunto considerado, são determinadas quais empresas são relativamente eficientes.

Outro modelo de DEA é chamado de BCC, abreviatura de Banker, Charnes e Cooper, que o desenvolveram e apresentaram em artigo publicado na Management Science em 1984. O modelo BCC pressupõe que as unidades avaliadas apresentem retornos variáveis de escala. Os retornos variáveis de escala consideram que o acréscimo em uma unidade de insumo pode gerar um acréscimo não proporcional no volume de produtos. Segundo Belloni (2000a: 68) "ao possibilitar que a tecnologia exiba propriedades de retornos à escala diferentes ao longo de sua fronteira, esse modelo admite que a produtividade máxima varie em função da escala de produção". A formulação matemática do Modelo BCC é: 
Maximizar $\sum_{r=1}^{m} u_{r} y_{r k}-u_{k}$,

sujeito a

$\sum_{i=1}^{n} v_{i} x_{i k}=1$

$\sum_{r=1}^{m} u_{r} y_{r j}-\sum_{i=1}^{n} v_{i} x_{i j}-u_{k} \leq 0$

$u_{r}, v_{i} \geq 0$

$y_{r j}=$ quantidadedo produtor produzida pela empresa $j$

$x_{i j}=$ quantidadedo insumo $i$ consumida pela empresa $j$

$y=$ quantidadede produtos $; x=$ quantidadedeinsumos $; u, v=$ pesos

$r=$ número de produtos $=1, \ldots, m ; i=$ número de insumos $=1, \ldots, n$

$j=$ número de empresas $=1, \ldots, N$

Percebe-se que é introduzida uma variável $u_{k}$ representando os retornos variáveis de escala. Essa variável não deve atender à restrição de positividade; pode, portanto, assumir valores negativos representando assim os retornos variáveis de escala.

É comum na literatura consultada a comparação dos resultados de Análise por Envoltória de Dados com os obtidos pela Análise de Regressão (Niederauer, 1998). A Análise de Regressão resulta em uma função que determina uma reta, no caso da Análise de Regressão Linear, que minimiza a soma dos erros quadrados (ou reta dos mínimos quadrados). É, portanto, uma reta que não representa necessariamente o desempenho de nenhuma das unidades analisadas. Essa comparação pode ser demonstrada pela Figura 3.

\section{Figura 3 - Comparação entre DEA e Análise de Regressão}

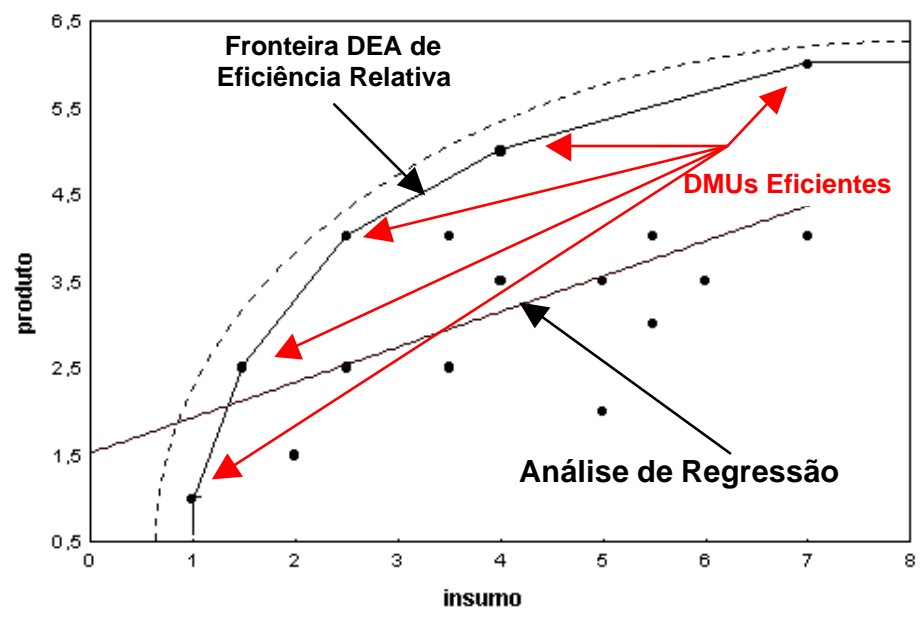

Fonte: NIEDERAUER, Carlos Alberto Pittaluga (1998) 
As observações individualmente estão representadas pelos pontos no gráfico. A reta traçada na Figura 3 é obtida da função resultante da Análise de Regressão Linear. Pode-se notar que apenas algumas observações posicionam-se próximas à reta de regressão.

A Análise por Envoltória de Dados define a curva de eficiência (ou de máxima produtividade), considerando a relação ótima insumo/produto. Assim, são identificadas as unidades que obtiveram a alocação ótima entre insumos e produtos, que são, então, chamadas de eficientes e são posicionadas na curva de máxima eficiência relativa. É importante notar que as demais unidades, não eficientes, estão posicionadas abaixo da curva, "envolvidas" pelo desempenho das unidades eficientes. O método define então unidades de referências para cada observação, o que permite calcular os aumentos na quantidade de produtos ou diminuição no consumo de insumos necessários para que a atuação seja otimizada.

Os resultados básicos de uma análise DEA são (Belloni, 2000b):

$$
\text { “(...) }
$$

- a identificação de um conjunto de unidades eficientes (que determinam a fronteira de eficiência);

- uma medida da ineficiência para cada unidade fora da fronteira (uma distância à fronteira que representa a potencialidade de crescimento da produtividade);

- as taxas de substituição (pesos) que determinam cada região da fronteira de eficiência e caracterizam as relações de valor que 'sustentam' a classificação dessa região como eficiente."

\section{Aplicação de Análise por Envoltória de Dados (DEA) em Análise de Demonstrações Contábeis}

Embora bastante difundida no exterior, onde mais de 400 trabalhos foram publicados no período de 1978 e 1992 (Charnes, Cooper, Lewin \& Seiford, 1997: 11), poucos estudos trataram especificamente da utilização da DEA em análise de demonstrações contábeis.

O estudo de Smith (1990) é uma das poucas referências no assunto, utilizando DEA em conjunto com a análise tradicional de indicadores contábeis para incorporar as diversas dimensões do desempenho empresarial. Outro artigo foi apresentado por Fernandez-Castro e S mith (1994) na busca de um modelo não paramétrico de desempenho corporativo. Feroz, Kim e Raab (2003) demonstraram que a DEA pode contribuir para a análise de indicadores tradicional, testando a hipótese nula de não há relacionamento entre a DEA e os indicadores contábeis tradicionais como medidas de desempenho de uma empresa. Os resultados obtidos rejeitaram hipótese nula indicando que a DEA traz informações para analistas que são complementares às advindas da análise de indicadores tradicional.

No Brasil o estudo pioneiro relacionando DEA e análise de demonstrações contábeis foi apresentado por Ceretta em 1999. O estudo aplica DEA às empresas do setor de alimentos brasileiro com base em dados da revista Exame - Melhores e Maiores. Em 2001, Ceretta e Niederauer utilizaram o método de análise por envoltória de dados na análise da rentabilidade e eficiência de 144 instituições bancárias no país. 
Os estudos citados revelam algumas das principais dificuldades da utilização da DEA em análise de demonstrações contábeis:

- Determinar os insumos e produtos que devem ser selecionados para inclusão no modelo;

- Decidir se os outliers oferecem representação genuína de uma tecnologia possível;

- Lidar com um pequeno número de observações;

- Fazer julgamentos sobre empresas que empregam uma combinação de insumos ou produtos pouco usual, que exige uma análise cuidadosa de resultados para determinar se um alto escore de eficiência advém de eficiência genuína ou da ausência de competidores comparáveis.

Outra dificuldade de aplicação da Análise por Envoltória de Dados em análise de demonstrações contábeis advém da impossibilidade de utilizar valores negativos. Alguns dos mais tradicionais indicadores contábeis assumem valores negativos. É o caso do resultado, que pode ser lucro (positivo) ou prejuízo (negativo). As medidas de retorno sobre patrimônio líquido e sobre ativo são gualmente derivadas do resultado e podem, portanto, assumir valores negativos. Assim como as medidas dinâmicas de evolução das vendas, por exemplo. E ainda indicadores financeiros como o capital circulante líquido.

Alguns autores propõem formas de superar essa limitação. Se o número de unidades sob avaliação é grande, pode-se avaliar a possibilidade de simples exclusão das unidades que tenham valores negativos em recursos e produtos.

Outra forma de superar o problema da utilização de valores negativos apóia-se na propriedade de alguns modelos DEA chamada de translation invariance (Ali e Seiford, 1990; Pastor, 1996; Knox Lovell e Pastor, 1995). Essa propriedade faz com que a solução do modelo não seja afetada por uma conversão (ou transformação) dos valores negativos em positivos. Assim, os escores de eficiência são mantidos, em alguns casos, ou a classificação em unidades eficientes e ineficientes é mantida, em outros casos.

A inclusão de variáveis com valores negativos na DEA foi primeiro tratada no artigo Translation Invariance in Data Envelopment Analysis de Ali e Seiford (1990). Os Modelos Aditivo e BCC são apresentados como portadores da propriedade que permitiria a tradução de valores negativos para variáveis, através da soma de uma constante, ressaltando-se que para o segundo "os escores de eficiência (valores da função objetivo) para as DMUs ineficientes serão diferentes quando os dados forem traduzidos” (Ali e Seiford, 1990: 405).

Em 1996, Pastor apresentou um adendo às conclusões anteriores de Ali e Seiford, provando que para o Modelo BCC a propriedade é limitada: quando se considera o modelo com orientação para o insumo, a tradução somente pode ser aplicada aos produtos; e no modelo com orientação para o produto, pode-se aplicar a transformação aos insumos.

Para lidar com o problema de variáveis que assumem valores negativos em DEA Ceretta e Niederauer (2001) prop useram uma modificação ao modelo original, dada pelas equações 9 a 13: 
Maximizar $z_{k}=\theta_{k}+\varepsilon\left(\sum_{r=1}^{m} s_{r}+\sum_{i=1}^{n} e_{i}\right)$,

sujeito a

$\theta_{k} y_{r k}-\sum_{i=1}^{n} \lambda_{j} y_{r j}+s_{r}=0$, se $y_{k}>0$

$\left(1-\theta_{k}\right) y_{r k}-\sum_{i=1}^{n} \lambda_{j} y_{r j}+s_{r}=0$, se $y_{k}<0$

$-x_{i k}+\sum_{i=1}^{n} \lambda_{j} x_{i j}+e_{i}=0$

$\lambda, s, r \geq 0$

$\theta=\exp$ ansãoequiproporional nos resultados

$\lambda=$ coeficientedo planode produção $\left(x_{j}, y_{j}\right)$

$s=$ fo $\lg$ as na produçãodos resultados

$e=$ excessosnoconsumode recursos

$y_{r j}=$ quantidadedo produtor produzida pela empresa $j$

$x_{i j}=$ quantidadedo insumo $i$ consumida pela empresa $j$

$y=$ quantidadede produtos $; x=$ quantidadedeinsumos

$\varepsilon=\inf$ initesimal não-arquimediano

$r=$ número de produtos $=1, \ldots, m ; i=$ número deinsumos $=1, \ldots, n$

$j=$ número de empresas $=1, \ldots, N$

O indicador de eficiência da empresa $k$ é dado pela seguinte equação geral:

$E f_{k}=\frac{\frac{p}{\theta}-\frac{n}{(\theta-1)}}{p+n}$,

onde:

$p=$ número de outputs positivos da empresa $k$

$n=$ número de outputs negativos da empresa $k$ 


\section{Apresentação do Modelo Proposto}

O modelo de Análise Estruturada de Demonstrações Contábeis - DEA proposto no presente estudo pode ser dividid o em algumas etapas e procedimentos relevantes, como demonstra a Figura 4.

Figura 4 - Metodologia proposta de análise estruturada de demonstrações contábeis - DEA

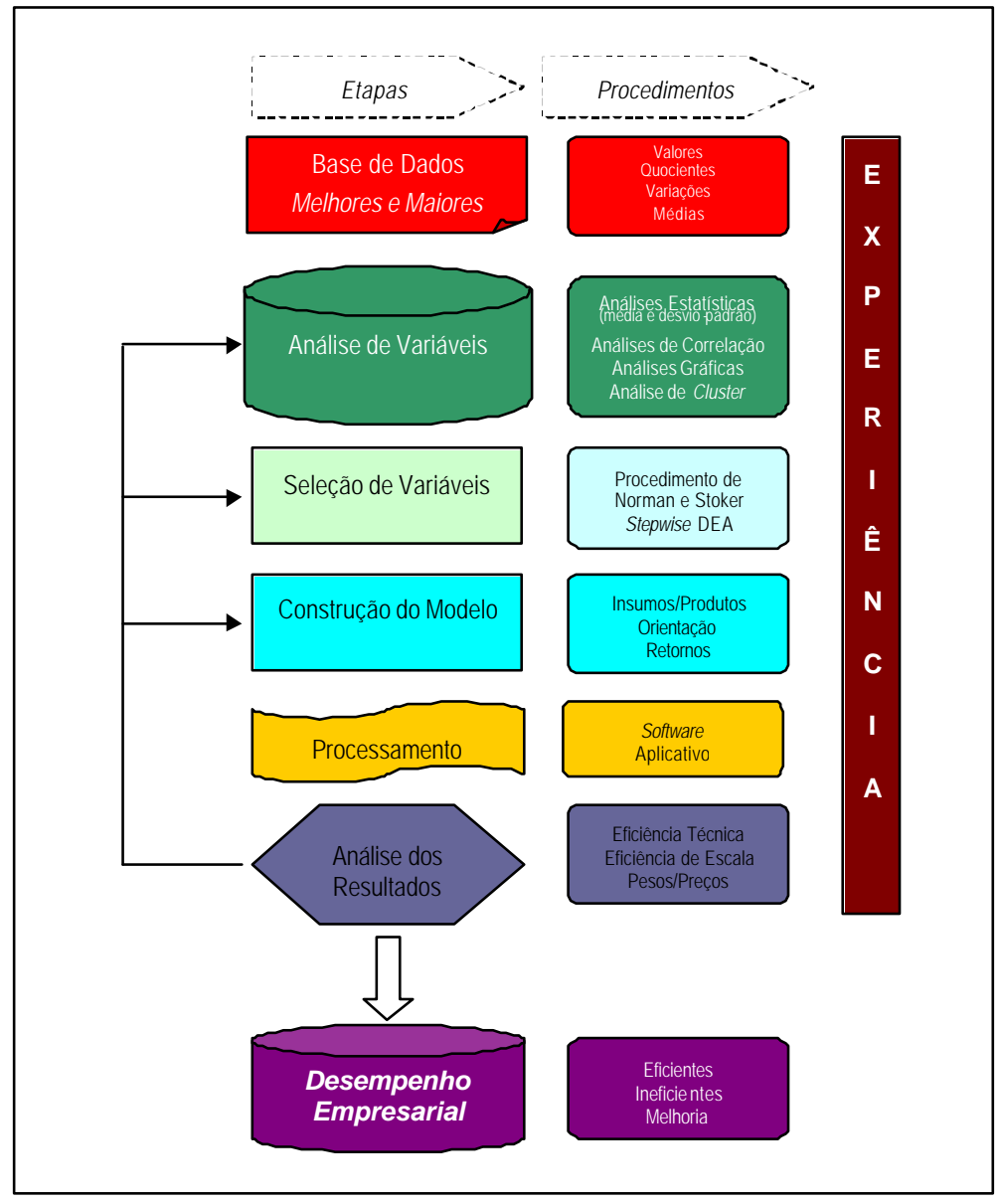

O processo inicia com o Levantamento das Informações, que podem ser valores (Ativo, Patrimônio, Número de funcionários) ou quocientes. Diversos autores apontam a vantagem dos quocientes por serem normalizados e não sofrerem influência do porte. Há a possibilidade ainda de considerar variações percentuais entre valores e média de períodos. É importante ressaltar que os modelos DEA são invariantes à escala, podendo incluir indicadores de diferentes medidas de mensuração. Os indicadores devem, no entanto, como já comentado, manter valores positivos, pois apenas alguns modelos permitem o ajuste para transformar as variáveis negativas em positivas sem alteração dos escores de eficiência. 
Na etapa de Análise de Variáveis, propõe-se a utilização de análises estatísticas, análises gráficas, análise de correlação e Análise de Cluster. As análises estatísticas servem para expandir o conhecimento do pesquisador sobre os indicadores. Foi verificado o nível de dispersão em torno da média que serve para atestar a qualidade do indicador como discriminador da atuação das empresas consideradas. A existência de outliers é cuidadosamente examinada e seu tratamento definido, sendo necessária às vezes a sua exclusão. A exclusão de outliers é justificada na literatura se for verificado que não representam uma opção de atuação factível para as demais empresas sob análise. A tendência é que os outliers posicionem-se na fronteira de eficiência, se positivos, causando impacto na avaliação das demais unidades.

A análise de correlação tem o objetivo de investigar relações de causalidade, que determinam insumos e produtos, ou a existência de informações redundantes. Como a análise DEA é afetada pelo número de variáveis do modelo, é extremamente relevante para a qualidade dos resultados que os indicadores sejam em número suficiente. Ficou comprovado em diversos estudos que quanto maior o número de variáveis do modelo, maior a possibilidade de uma unidade alcançar a fronteira de eficiência relativa. Isso se explica pela expansão das possibilidades de combinações que permite a maximização da eficiência. Outra indicação constante na literatura é que o número de unidades avaliadas seja, no mínimo, duas vezes a soma do número de insumos e produtos que compõem o modelo (Fitzsimmons \& Fitzsimmons, 2000: 402).

Para definir o conjunto de empresas para compor a análise é utilizada a Análise de Cluster. Conforme indicações na literatura, as unidades sob exame devem ser homogêneas (Golany \& Roll, 1998: 239), ou seja: executam os mesmos processos, com objetivos semelhantes; estão sujeitas às mesmas condições de mercado; utilizam os mesmos inputs e outputs, exceto por variações de intensidade ou magnitude.

Através das análises gráficas, explor a-se o relacionamento entre as variáveis para determinar a presença de retornos constantes ou variáveis à escala.

A Seleção de Variáveis é feita com utilização de técnicas estatísticas: procedimento de Norman \& Stoker (1991) e Stepwise DEA (Kittelsen, 1993). As técnicas, aliadas à experiência do pesquisador, permitem a seleção dos insumos e produtos a compor o modelo. Vale registrar um comentário a respeito do período de estudo: na revisão da literatura sobre DEA muitas variações são percebidas. As unidades sob avaliação podem ser consideradas para apenas um ano ou período. No caso de considerar vários anos ou períodos, pode-se: (1) calcular a média das variáveis (Shafer \& Byrd , 1999); (2) tratar as unidades em cada ano como unidades "virtuais" (Yunos \& Hawdon, 1997); ou, ainda, (3) considerar o conjunto completo de dados, entrando com a empresa em cada ano como se fosse uma empresa diferente e multiplicando, portanto, a base de dados (Migon, 2000).

Para a Construção do Modelo, além da definição de insumos e produtos, é determinada a orientação, maximização de produtos ou minimização de insumos, e se os retornos de escala são constantes ou variáveis. Em algumas ocasiões, não é possível minimizar a alocação de recursos; assim, o modelo necessariamente considerará orientação ao output, como no estudo de Belloni (2000b) sobre as universidades federais, no qual não havia sentido minimizar recursos como número de professores ou número de artigos publicados, mas estudar a melhor alocação possível de recursos, em prol da maximização de resultados. A definição do modelo e de sua orientação também pode ser influenciada pela necessidade de efetuar transformação de escala em inputs ou outputs (Simak , 1997; Simak, 2000; Shafer \& Byrd, 1999). 
Após o Processamento do Modelo, faz-se a Análise dos Resultados. As empresas eficientes foram determinadas e estudada sua importância na formação do grupo de referência. Para as empresas ineficientes, são avaliadas as possibilidades de melhoria. A análise de resultados indica, ainda, a necessidade de adaptações e aperfeiçoamentos ao modelo. Por isso, na Figura 3, que apresenta esquematicamente as etapas e os procedimentos da metodologia proposta, as setas representam a retroalimentação de cada etapa pelos resultados das etapas subseqüentes. O processo é repetido até que não sejam possíveis aperfeiçoamentos ao modelo DEA.

\section{Aplicação do Modelo DEA Proposto}

\section{Setor em Estudo}

Para aplicação da metodologia proposta foi utilizado o setor de energia elétrica que tem representação praticamente censitária na Base de Dados Melhores e Maiores de Fipecafi-Exame. A base contém informações de 46 empresas, para o período de 1999 a 2000, que correspondem a 60,53\% das empresas, $96 \%$ do consumo total, $84 \%$ do consumo próprio e $96 \%$ do mercado de distribuição do setor de energia elétrica (Aneel - Participação das Empresas no Mercado de Distribuição (Versão Preliminar) - Exercício 1999).

\section{Variáveis}

O propósito do estudo foi testar a metodologia proposta para construção um modelo DEA para aplicação ao processo de análise de balanços e concluir sobre sua utilidade e limitações. Para tanto, a base de comparação foi o levantamento Melhores e Maiores de Fipecafi-Exame. O índice de Excelência Empresarial utilizado para aferição do desempenho das empresas em Melhores e Maiores é calculado pela ponderação dos seguintes indicadores:

\section{Quadro 1 - Descrição dos indicadores de excelência empresarial}

\begin{tabular}{|c|c|c|}
\hline Indicador & Peso & Descrição \\
\hline Liderança de mercado & 10 & $\begin{array}{l}\text { Divisão das vendas em dólares da empresa pela soma das } \\
\text { vendas em dólares das empresas pesquisadas incluídas no } \\
\text { setor, em porcentagem }\end{array}$ \\
\hline Crescimento de vendas & 10 & $\begin{array}{l}\text { Crescimento (ou redução) da receita bruta de vendas e } \\
\text { serviços em reais, descontada a inflação, medida pelo IGP-M }\end{array}$ \\
\hline Rentabilidade do PL & 25 & $\begin{array}{l}\text { Resultado líquido dividido pelo patrimônio líquido, ajustados } \\
\text { pela inflação, em porcentagem }\end{array}$ \\
\hline Liquidez Corrente & 15 & $\begin{array}{l}\text { Ativo circulante dividido pelo passivo circulante, em número- } \\
\text { índice }\end{array}$ \\
\hline Inve stimento no Imobilizado & 20 & $\begin{array}{l}\text { Aquisições de imobilizado do período (obtidas na DOAR) } \\
\text { divididas pelo ativo imobilizado do período anterior, ajustados } \\
\text { pela inflação, em porcentagem }\end{array}$ \\
\hline Riqueza criada por empregado & 20 & $\begin{array}{l}\text { Riqueza total gerada pela empresa no período (obtida na } \\
\text { DVA) dividida pela média aritmética no número de } \\
\text { funcionários, em dólares }\end{array}$ \\
\hline
\end{tabular}


Para montagem do modelo DEA os indicadores podem ser utilizados como são (Smith, 1990), ou podem ser desdobrados em input e output (Simak, 1997, 2000). Para a construção do primeiro modelo, foram utilizadas as variáveis apresentadas no Quadro 1, que mostra ainda o indicador do qual foram derivadas e sua classificação como recurso ou produto.

Quadro 2 - Indicadores de Melhores e Maiores adaptados

\begin{tabular}{l|l|l|}
\hline Variável & Utilizado no Indicador & Classificação \\
\hline Vendas & Liderança & Output \\
\hline Lucro Líquido Ajustado & Retorno sobre o PL & Output \\
\hline Retorno sobre o PL & Retorno sobre o PL & Output \\
Valor Adicionado & Riqueza por Empregado & Output \\
\hline Valor Adicionado por Empregado & Riqueza por Empregado & Output \\
\hline Ativo Circulante & Liquidez Corrente & Output \\
\hline Liquidez Corrente & Liquidez Corrente & Output \\
\hline Capital Circulante Líquido & Liquidez Corrente & Output \\
\hline Crescimento de Vendas (\%) & Crescimento de Vendas & Output \\
\hline Crescimento de Vendas (US\$) & Crescimento de Vendas & Output \\
\hline Investimento no Imobilizado (\%) & Investimento no Imobilizado & Output \\
\hline Aplicação no Imobilizado (US\$) & Investimento no Imobilizado & Output \\
\hline Patrimônio Líquido Ajustado & Retorno sobre PL & Input \\
\hline Passivo Circulante & Liquidez Corrente & Input \\
\hline Ativo Imobilizado - Ano Anterior & Investimento no Imobilizado & Input \\
\hline Número Médio de Empregados & Riqueza por Empregado & Input \\
\hline
\end{tabular}

\section{Seleção de Variáveis}

A seleção de variáveis é um dos pontos mais discutidos em DEA. Bowlin (1998: 19) identifica-a como "consideração-chave na utilização da DEA. Escolher inputs e outputs corretos é importante para a efetividade da interpretação, utilização e aceitação dos resultados da Análise DEA pelos gestores e outras partes afetadas".

Foi aplicado um procedimento que considera as etapas previstas por Norman \& Stoker (1991) e por Kittelsen (1993), conjuntamente. Entre os testes de significância de médias propostos por Kittelsen (1993), foi utilizado o Teste $t$, com a fórmula: 


$$
t=\frac{\operatorname{Média}\left(E_{i}^{1}\right)-\operatorname{Média}\left(E_{i}^{0}\right)}{\sqrt{\frac{N^{1} \operatorname{Var}\left(E_{i}^{1}\right)+N^{0} \operatorname{Var}\left(E_{i}^{0}\right)}{N^{1}+N^{0}-2}\left[\frac{1}{N^{1}}+\frac{1}{N^{0}}\right]}},
$$

onde:

$E^{0}=$ Indicador de eficiência na Etapa 0

$E^{1}=$ Indicador de eficiência na Etapa 1

$i=1$ a $N$

$\mathrm{N}^{0}=$ número de empresas na Etapa 0

$\mathrm{N}^{1}=$ número de empresas na Etapa 1

graus de liberdade $=N^{1}+N^{0}-2$

Assim, as etapas foram: (1) determinar o par inicial de input e output com base na análise de correlação; (2) calcular os indicadores de eficiência para as empresas; (3) efetuar a análise dos critérios para inclusão de variáveis; (4) determinar variável a ser incluída, retomando do passo (2), enquanto sejam indicadas mais variáveis como relevantes para compor o modelo.

Como proposta, e considerando a importância de uma análise cuidadosa de inserção de variáveis, os critérios e as bases de julgamento observadas foram:

\section{Quadro 3 - Critérios e base de julgamento}

\section{Critérios de análise}

Análise de correlação entre as variáveis de input e output e o indicador de eficiência calculado na etapa imediatamente anterior;

Efeito da inclusão de cada variável na média do indicador de eficiência das empresas;

Variação ocorrida na média do indicador de eficiência entre as etapas;

Número de empresas com indicador de eficiência igual a $100 \%$;

Número de empresas com indicador de eficiência menor que $50 \%$;

Resultados do Teste $t$ de significância da diferença entre as eficiências médias.

\section{Base de julgamento para inclusão da variável}

Variável com o maior índice de correlação com o indicador de eficiência;

Variável cuja inclusão resultar na maior eficiência média;

Variável cuja inclusão resultar na maior variação na eficiência média entre as etapas;

Variável cuja inserção implicar o maior número de empresas com indicador de eficiência igual a $100 \%$ (são as empresas consideradas relativamente eficientes pelo modelo);

Variável cuja inserção implicar no menor número de empresas com indicador de eficiência menor que $50 \%$;

Será considerada a variável cuja comparação entre as médias resultar em diferenças significativas entre as etapas; para tanto, serão considerados o $\mathrm{t}_{\text {calculado }} \mathrm{e}$ o $\mathrm{t}_{\text {crítico }}$ ou $t_{\text {tabelado, }}$, considerando os graus de liberdade da formulação (9) e o alfa (nível de significância) desejado. 
Os critérios podem indicar decisões diversas. Assim, optou-se por admitir que fossem incluídas em cada etapa a variável indicada pela maioria dos critérios. Os critérios foram aplicados para os dois anos em análise, 1999 e 2000, simultaneamente.

\section{Construção do Modelo}

Foi efetuada a análise de correlação entre as variáveis para definição do par inicial de input e output. A Tabela 1 apresenta as correlações mais significativas entre as variáveis de input e output.

Tabela 1 - Resumo da correlação entre input e output

\begin{tabular}{|c|c|c|c|}
\hline & Lucro & $\begin{array}{l}\text { Valor } \\
\text { onado }\end{array}$ & Vendas \\
\hline \multicolumn{4}{|c|}{1998} \\
\hline PLAjustado & 0,424 & 0,565 & 0,590 \\
\hline$N^{o}$ Empregados & 0,327 & 0,718 & 0,741 \\
\hline \multicolumn{4}{|c|}{1999} \\
\hline PL Ajustado & 0,146 & 0,617 & 0,582 \\
\hline Média de Empregados & 0,147 & 0,720 & 0,778 \\
\hline \multicolumn{4}{|c|}{2000} \\
\hline PL Ajustado & 0,448 & 0,499 & 0,564 \\
\hline Média de Empregados & 0,561 & 0,909 & 0,801 \\
\hline
\end{tabular}

A escolha para compor o par inicial de input x output recaiu sobre Média de Empregados e Valor Adicionado. Foi construído o modelo inicial com variáveis Média de Empregados (input) e Valor Adicionado (output). A Tabela 2 mostra os resultados da análise, para os anos de 2000 e 1999, para o modelo inicial, a primeira etapa de inclusão de variáveis e o modelo final.

Tabela 2 - Resultados dos modelos DEA em cada etapa

\begin{tabular}{|c|c|c|c|c|c|c|}
\hline Variáveis & \multicolumn{2}{|c|}{ Modelo Inicial } & \multicolumn{2}{|c|}{$1^{\mathrm{a}}$. Etapa } & \multicolumn{2}{|c|}{ Modelo Final } \\
\hline Anos & 2000 & 1999 & 2000 & 1999 & 2000 & 1999 \\
\hline Eficiência Média & 40,6 & 19,3 & 53,5 & 53,0 & 81,4 & 81,4 \\
\hline Desvio-padrão da eficiência & 30,5 & 21,8 & 27,2 & 28,4 & 21,5 & 20,7 \\
\hline Coeficiente de Variação & 0,8 & 1,1 & 0,5 & 0,5 & 0,3 & 0,3 \\
\hline Variância & 927,4 & 474,4 & 740,9 & 809,3 & 461,6 & 426,5 \\
\hline Mínimo & 3,0 & 4,3 & 6,0 & 6,9 & 44,5 & 31,0 \\
\hline $1^{\circ}$ Quartil & 16,1 & 9,4 & 34,7 & 34,7 & 55,4 & 67,3 \\
\hline Mediana & 33,8 & 12,9 & 43,4 & 44,1 & 100,0 & 84,1 \\
\hline $3^{\circ}$ Quartil & 57,4 & 16,9 & 72,5 & 73,4 & 100,0 & 100,0 \\
\hline Máximo & 100,0 & 100,0 & 100,0 & 100,0 & 100,0 & 100,0 \\
\hline Número de Empresas Eficientes & 3 & 2 & 6 & 7 & 20 & 17 \\
\hline Empresas Indicador Eficiência $<50 \%$ & 25 & 36 & 21 & 25 & 1 & 4 \\
\hline Variação da Eficiência Média & & & 12,9 & 33,7 & 2,1 & 5,9 \\
\hline
\end{tabular}


Os resultados da análise para cada ano foram bastante diversos (colunas 2 e 3 - Tabela 2): para o ano de 1999 mostrou eficiência média de 19,3\%, para o conjunto de empresas, com apenas 2 empresas eficientes e 36 empresas com indicador de eficiência menor que 50\%; para o ano de 2000, a eficiência média foi de 40,6\% com 3 empresas eficientes e 25 empresas com indicador inferior a 50\%.

A Tabela 3 resume as informações para a primeira etapa, em que foi escolhida a terceira variável a compor o modelo. Para o Teste $t$ foi considerado o valor crítico de 1,6651506, com 76 graus de liberdade e alfa de 0,05. Estão em destaque os critérios de inclusão para cada variável.

Tabela 3 - Informações para a primeira etapa de inclusão de variáveis

\begin{tabular}{|c|c|c|c|c|c|c|c|c|c|c|c|}
\hline Análise das Variáveis & Correlação & Més & $\overline{d i a}$ & $\overline{\text { Var. } 1}$ & $\overline{\text { Média }}$ & $\mathbf{E}=$ & $100 \%$ & $\mathbf{E}<$ & $50 \%$ & & tet \\
\hline & $2000 \quad 1999$ & 2000 & 1999 & 2000 & 1999 & 2000 & 1999 & 2000 & 1999 & 2000 & 1999 \\
\hline Vendas & $0,5919-0,0375$ & 44,6 & 35,5 & 4,0 & 16,2 & 4 & & 25 & 32 & 20,5726 & 2,9265 \\
\hline Lucro Líquido & $0,4176 \quad 0,3039$ & 43,1 & 19,9 & 2,5 & 0,6 & 6 & & 25 & 36 & $5 \quad 0,3465$ & 0,1170 \\
\hline Retorno & $0,3607 \quad 0,0397$ & 43,1 & 26,2 & 2,5 & 6,9 & 6 & & 24 & & $\begin{array}{ll}3 & 0,3442\end{array}$ & 1,1235 \\
\hline Liquidez Corrente & $-0,3042-0,1347$ & 52,2 & 33,0 & 11,6 & 13,6 & 5 & & 19 & 32 & $\begin{array}{l}21,6535 \\
\end{array}$ & 2,2699 \\
\hline$\overline{\mathrm{CCL}}$ & $-0,2913 \quad 0,0193$ & 55,4 & 31,6 & 14,8 & 12,3 & 7 & 5 & 17 & & 22,0801 & 2,0620 \\
\hline $\begin{array}{l}\text { Crescimento de } \\
\text { Vendas (\%) }\end{array}$ & $-0,1999-0,5853$ & 54,2 & 47,4 & 13,6 & 28,1 & 7 & 8 & 20 & 26 & $5 \quad 1,9295$ & 4,4163 \\
\hline $\begin{array}{l}\text { Crescimento de } \\
\text { Vendas (US\$) }\end{array}$ & $0,0182-0,5036$ & 45,5 & 42,2 & 4,9 & 22,9 & 5 & 7 & 25 & 29 & 0,6932 & 3,6710 \\
\hline $\begin{array}{l}\text { Tnvestimento no } \\
\text { Imobilizado }\end{array}$ & $-0,2260-0,1466$ & 57,0 & 26,2 & 16,4 & 6,9 & 9 & & 17 & 34 & 42,2709 & 1,2198 \\
\hline $\begin{array}{l}\text { Aplicação no } \\
\text { Imobilizado }\end{array}$ & $0,3004-0,0209$ & 52,1 & 31,4 & 11,5 & 12,1 & 7 & & 21 & 32 & $2 \quad 1,6088$ & 2,1514 \\
\hline PL Ajustado & $0,2673 \quad 0,1274$ & 53,5 & 53,0 & 12,9 & 33,7 & 6 & 7 & 21 & 25 & 1,9459 & 5,7953 \\
\hline
\end{tabular}

Assim, para a variável PL Ajustado existiram 10 indicações (indicadas em negrito). A variável Crescimento de Vendas em percentual recebeu indicações em todos os critérios. No entanto, analisando-se as eficiências médias obtidas com a inclusão de PL Ajustado e de Crescimento de Vendas, percebeu-se que o modelo obtido com a inserção da primeira é mais homogêneo para os anos de 2000 e 1999. Assim, deutse preferência a sua indicação.

Ressalte-se ainda que, se considerado apenas o resultado da análise de correlação para o ano de 2000, a variável a compor o modelo seria Vendas que, no entanto, mostrou correlação pequena com o indicador de eficiência calculado para o ano de 1999. E se utilizados apenas os resultados do Teste $t$ para o ano de 1999, a escolha recairia entre as variáveis Vendas, Liquidez Corrente, CCL, Crescimento de Vendas em percentual, Crescimento de Vendas em dólares, Aplicação no Imobilizado ou PL Ajustado. 
Somente CCL, Crescimento de Vendas em percentual e PL Ajustado permaneceram significativas com os resultados para o ano de 2000.

Os resultados obtidos com a inclusão de PL Ajustado como input são apresentados na Tabela 2, colunas intermediárias (4 e 5). O modelo tormou-se mais homogêneo para os anos em análise, com 6 e 7 empresas eficientes e 21 e 25 empresas com indicador inferior a 50\%, para 2000 e 1999, respectivamente.

Repetiu-se esse procedimento até o ponto de parada. Neste ponto os acréscimos na eficiência média com a inserção das variáveis candidatas a inclusão são pequenos. A análise de correlação não indic ou qualquer variável como relevante. A variável indicada pelo Teste $t$ (CCL) reflete a situação financeira da empresa, que já estava contemplada pela inclusão da variável Liquidez Corrente no modelo. Assim, o modelo final considerou as variáveis:

Outputs: Valor Adicionado; Liquidez Corrente; Crescimento de vendas em percentual; Aplicação no Imobilizado

Inputs: PL Ajustado; Média de Empregados.

Os resultados do modelo final estão resumidos na Tabela 2, nas duas últimas colunas (6 e 7). A eficiência média das empresas atingiu $81,4 \%$ para os dois anos. Os resultados tornaram se mais homogêneos com 20 e 17 empresas classificadas como eficientes em 2000 e 1999, respectivamente.

\section{ANÁLISE DOS RESULTADOS}

\section{Comparação com o indicador de Excelência Empresarial de Melhores e Maiores}

As avaliações obtidas pelo indicador de Excelência Empresarial de Melhores e Maiores e pelo modelo DEA são contrapostas na Figura 5 para o ano de 2000. A divisão da Figura em quadrantes teve por finalidade diferenciar os pontos de concordância e de discordância entre as avaliações. Foram traçados como limites para definição dos quadrantes $90 \%$ para o indicador DEA e $70 \%$ para o indicador de Excelência Empresarial de Melhores e Maiores. Com o limite em 70\%, segregam-se as melhores empresas, seguindo-se os critério s adotados por Melhores e Maiores para a escolha da melhor empresa de cada setor. Essa definição considerou, ainda, as diferenças entre os indicadores: enquanto pode ser atribuído o indicador de eficiência DEA igual a $100 \%$ para mais de uma empresa, o indicador de Excelência Empresarial foi calculado proporcionalmente, tendo como base 100 o máximo de pontos atribuídos às empresas do grupo. Assim, apenas uma empresa pôde ter o indicador de Excelência Empresarial igual a 100\%, em cada ano. Na Figura, os quadrantes indicados por II e IV são aqueles em que os indicadores diferem. Nos quadrantes I e III, as avaliações dos indicadores aproximam-se. A Figura 6 mostra as mesmas informações para 1999. No canto superior direito, em ambas as Figuras, o ponto extremo é representado pelas empresas que receberam indicador 100\% nas duas análises: Cerj, em 1999, e Cosern, em 2000. 
Figura 5 - Indicador DEA x Excelência Empresarial - 2000 - energia elétrica

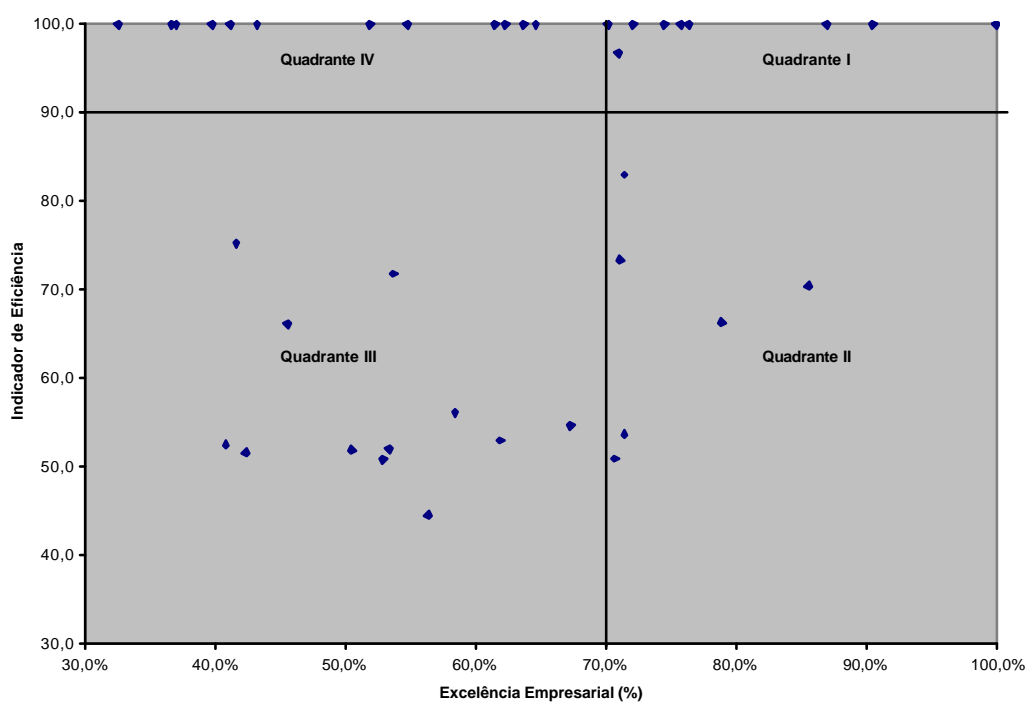

Figura 6 - Indicador DEA x Excelência Empresarial - 1999 - energia elétrica

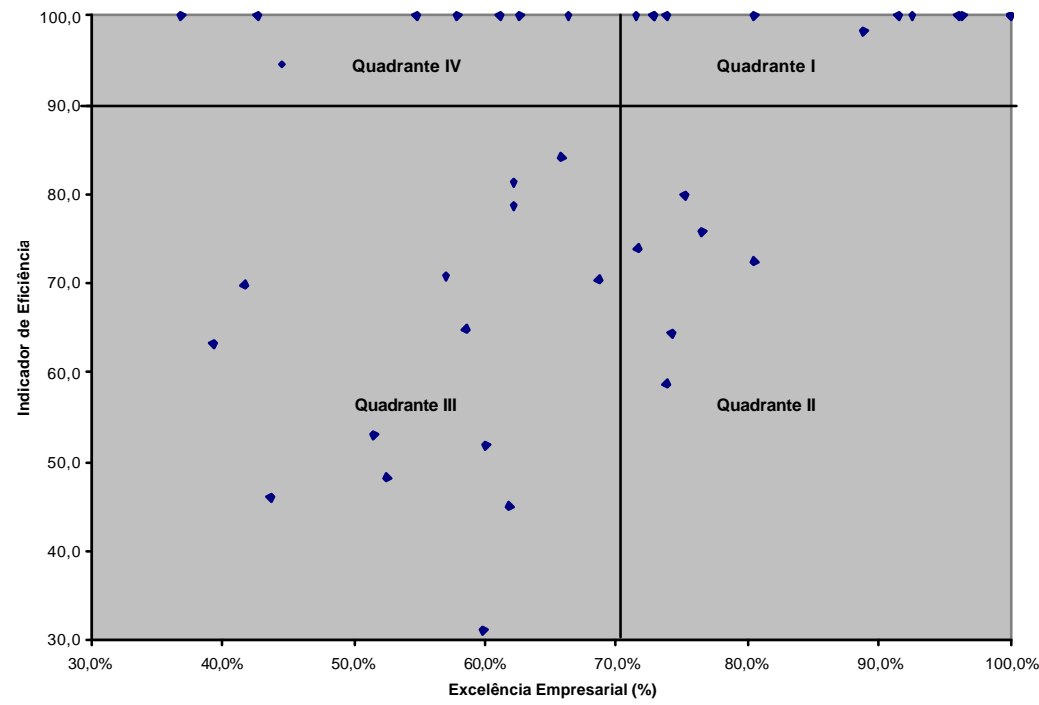


A Tabela 4 mostra a distribuição das empresas entre os quadrantes.

Tabela 4 - Distribuição das empresas em quadrantes - energia elétrica

Número de Empresas $\quad \%$ de Empresas

\begin{tabular}{l|rrrr}
\cline { 2 - 5 } & 2000 & 1999 & 2000 & 1999 \\
Quadrante I & 9 & 11 & $23 \%$ & $28 \%$ \\
Quadrante II & 6 & 6 & $15 \%$ & $15 \%$ \\
Quadrante III & 12 & 14 & $31 \%$ & $36 \%$ \\
Quadrante IV & 12 & 8 & $31 \%$ & $21 \%$ \\
Total & $\mathbf{3 9}$ & $\mathbf{3 9}$ & $\mathbf{1 0 0 \%}$ & $\mathbf{1 0 0 \%}$
\end{tabular}

A preocupação foi explorar os quadrantes II e IV que apresentaram divergências entre as avaliações para cada um dos critérios. No total, foram 18 empresas em 2000 (46\%) e 14 empresas em 1999 (36\%).

No quadrante II, empresas classificadas como eficientes pelo critério de Excelência Empresarial receberam indicador de eficiência menor que $90 \%$ pela Análise DEA. No quadrante IV, empresas com indicador de eficiência acima de $90 \%$ pelo Modelo DEA receberam indicador de Excelência Empresarial menor que $70 \%$.

Como exemplo das divergências entre as análises, pode-se citar a empresa Eletronuclear, classificada como eficiente nos dois anos pela DEA, com indicador de Excelência Empresarial de 41,2\% em 2000 e $36,8 \%$ em 1999. Sua classificação como eficiente corresponde à sua atuação em relação ao grupo. Em 2000, com PL Ajustado de US\$ 3.176 .120 mil, sua atuação aproximou-a da Copel (PL Ajustado de US\$ 3.610.374 mil). No entanto, alcanç ou seus resultados com 1.772 funcionários, enquanto a Copel tem 6.342 colaboradores. Para atingir a fronteira de eficiência, atribuiu maior peso $(79 \%)$ ao output Crescimento de Vendas em percentual, que foi o máximo do grupo para o ano. A Copel teve, no mesmo período, 8,5\% de Crescimento de Vendas. No indicador de Excelência Empresarial, atingiu o máximo de pontos apenas em Crescimento de Vendas em percentual. Nos demais indicadores, apareceu posicionada em torno de $10^{\circ}$. lugar, com exceção de Valor Adicionado, em que apareceu apenas na $2^{\mathrm{a}}$. posição, em penúltimo lugar, portanto.

Outra diferença entre as avaliações pode ser ressaltada pela análise da empresa CNEE. Com o valor mínimo do grupo em PL Ajustado (US\$ 30.070 mil em 2000) e apenas 139 funcionários foi classificada como eficiente nos dois anos pela Análise DEA. Em 2000 atribuiu maior peso ao Valor Adicionado (99,99\%). Em 1999 distribuiu os pesos aos outputs Liquidez Corrente (48\%), Valor Adicionado (25\%) e Aplicação no Imobilizado (25\%). Essa é uma das características da Análise DEA. Cada uma das empresas é avaliada individualmente e atribui para inputs e outputs os pesos que mais valorizam sua posição relativa ao grupo. Assim, "é colocada sob a melhor luz" (Smith, 1990: p. 133). No entanto, considerando o indicador de Excelência Empresarial, teve pontuação mínima em Liderança de Mercado e foi penúltima colocada em Liquidez Corrente. Em Riqueza Criada e Investimento no 
Imobilizado, obteve o $21^{\circ}$ lugar. Em Crescimento de Vendas, ficou com na $26^{\mathrm{a}}$ posição. Sua melhor colocação foi em Retorno do Investimento: $32^{\circ}$ lugar. Somou ao todo, em 2000, após a ponderação, 1.940 pontos; o máximo de pontos foi de 3.155, o que dá a CNEE $61 \%$ de indicador de Excelência Empresarial.

Em 1999, a empresa EEB, uma das menores empresas do setor, atingiu 73,8\% de indicador de Excelência Empresarial, participando do grupo de melhores empresas pelo critério de corte adotado (70\%). Mas, analisando os casos das empresas de menor porte, abre-se uma questão: o indicador de Excelência Empresarial privilegia as empresas de maior porte?

O PL Ajustado em 2000, para as melhores empresas considerando o indicador de Excelência Empresarial, variou entre US\$ 245.060 mil e US\$ 5.999.137 mil. Segundo a Análise DEA, a variação mostrada é de US\$30.070 mil a US\$ 6.525.799 mil. É uma indicação de que as empresas de menor porte têm maior probabilidade de participar do grupo de empresas eficientes pela Análise DEA?

No ano de 1999, as melhores empresas pelo critério de Excelência Empresarial tiveram o PL Ajustado variando entre US\$ 53.842 mil e US\$ 8.067.146 mil. Para a Análise DEA, o conjunto de empresas eficientes inclui igualmente a empresa de menor PL Ajustado, a CNEE. Novamente houve a indicação de que as empresas de menor porte estão mais presentes na Análise DEA.

Os indicadores que foram incluídos na ponderação da Excelência Empresarial são influenciados pelo porte? Pela utilização de um dos indicadores, a Liderança de Mercado, sem dúvida. E esse indicador tem peso 10 na ponderação. E os demais indicadores? Rentabilidade, Crescimento de Vendas em percentual, Investimento no Imobilizado em percentual e Riqueza criada por empregados estão "normalizados" pelos denominadores, respectivamente, PL Ajustado, Vendas, Ativo Imobilizado e Número de Empregados. Não são influenciados, portanto, pelo porte. Liquidez Corrente é o quociente entre Ativo Circulante e Passivo Circulante, resultando em um número-índice, também isento da influência do porte da empresa. Assim, concluiu-se que as empresas de maior porte estiveram em vantagem em relação a um indicador considerado, Liderança de Mercado, que contribuiu com peso 10 na composição do indicador de Excelência Empresarial.

Já a Análise DEA permitiu à empresa individualmente determinar os pesos que foram atribuídos a cada indicador, de forma a maximizar seu indicador de eficiência. Além disso, puderam ser considerados os retornos à escala que melhor atenderam à configuração da atuação do setor.

\section{Comparação com o indicador de Retorno sobre o Patrimônio Líquido}

Finalmente, para concluir, apresenta-se a comparação do indicador de eficiência DEA com o Retorno sobre o Patrimônio Líquido, indicador contábil tradicional e entre os mais citados no sucesso empresarial. As Figuras 7 e 8 mostram a contraposição entre indicador de eficiência calculado pela Análise DEA e o Retorno sobre o PL obtido pelas empresas do setor energia elétrica. 
Figura 7 - Retorno versus Indicador de Eficiência - 2000 - energia elétrica

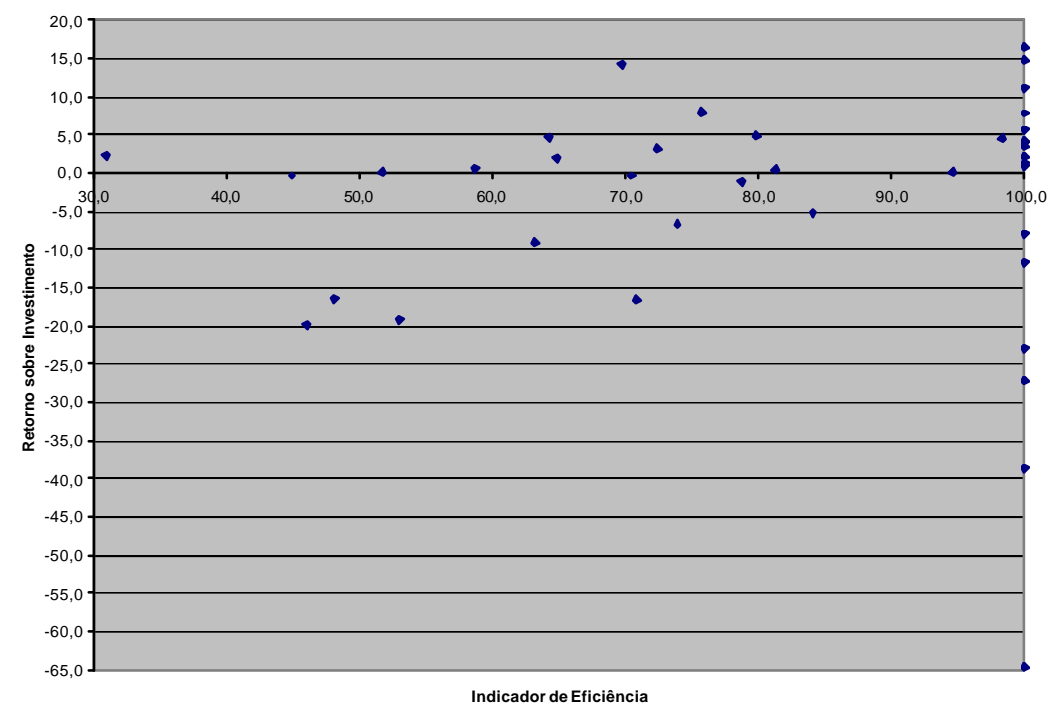

Figura 8 - Retorno versus Indicador de Eficiência - 1999 - energia elétrica

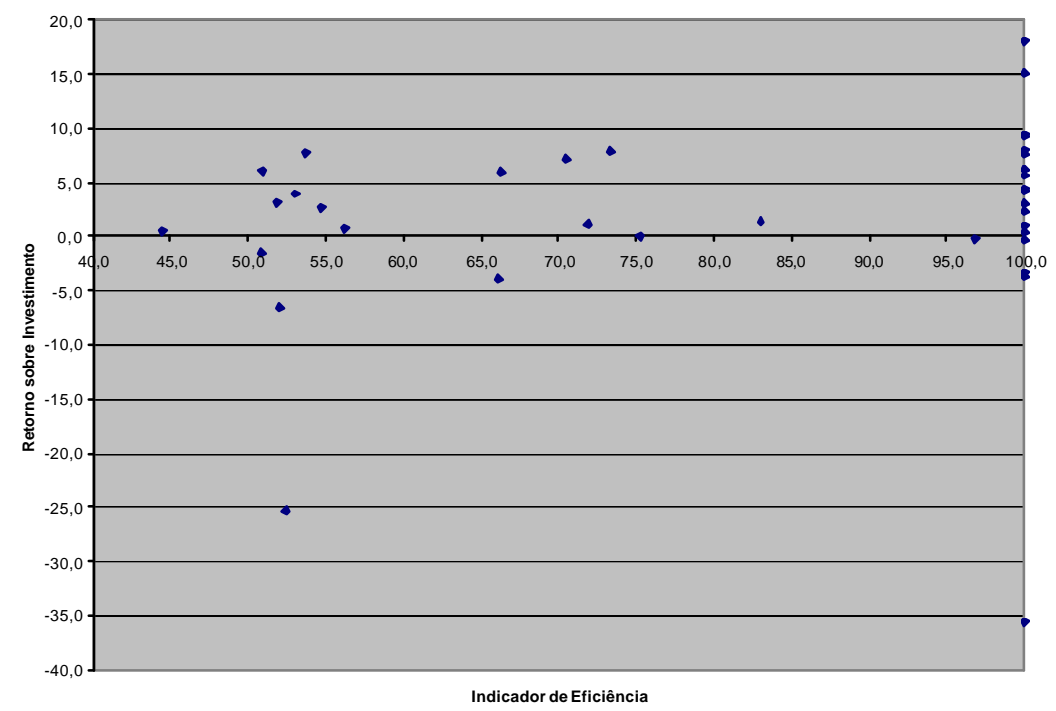


Para o ano de 2000, as empresas eficientes distribuíram-se no lado direito do gráfico com retornos entre $18,1 \%$ e $-35,5 \%$. Para 1999, a variação foi ainda maior: entre $16,4 \%$ e $-64,6 \%$.

Escolhido por muitos especialistas como o principal indicador do desempenho empresarial, o Retorno sobre o Patrimônio Líquido representou uma das facetas da atuação empresarial: o resultado da empresa. A DEA possibilitou uma análise multidimensional do desempenho empresarial, incluindo as diversas facetas consideradas relevantes para a determinação da eficiência relativa de cada empresa que compôs o grupo.

\section{CONCLUSÕES}

No presente estudo propôs-se uma contribuição à análise de demonstrações contábeis com uma proposta de utilização de Análise por Envoltória de Dados, apresentando-se uma metodologia que relacionou etapas e procedimentos para estruturação de um modelo DEA, partindo-se de informações contábeis.

A metodologia foi aplicada em um conjunto de empresas do setor elétrico brasileiro para os anos de 1999 e 2000. Os escores de eficiência obtidos para as empresas foram comparados com o indicador de Excelência Empresarial de Melhores e Maiores e com o retorno sobre o investimento, indicador contábil tradicional, para exploração de vantagens e limitações. Entre as vantagens da utilização da análise DEA estão:

○ Prescinde de atribuição prévia de pesos às variáveis consideradas no estudo;

- A eficiência de cada empresa é definida de forma individualizada, considerando a atuação das demais em estudo, porém permitindo que a alocação de pesos aos fatores fosse efetuada de forma a maximizar sua eficiência relativa;

- As diferenças de porte podem ser tratadas com a adoção de modelos com retornos variáveis à escala, sem prejuízo às empresas de pequeno porte;

- Diferentemente dos sistemas de atribuição de pontos, mais de uma empresa pode ser classificada como eficiente, compondo a fronteira de eficiência relativa e servindo como referência para a atuação das demais empresas;

- Permite uma visão multifacetada da eficiência e possibilita a análise dos fatores que mais contribuíram para seu atingimento.

A principal limitação identificada na aplicação da DEA é o fato de ser técnica ainda recente, quase restrita às áreas de pesquisa operacional e engenharia, e necessitando de ambientação dos usuários leigos para utilização em outras áreas do conhecime nto.

Finalmente, um comentário deve ser feito em favor da complementaridade dos métodos. As metodologias de avaliação de desempenho empresarial estão em constante evolução e, apesar de ondas 
e modismos, nenhuma se sobrepôs às demais no decorrer do tempo. Ressalta-se a consideração de utilizá-las complementarmente explorando as divergências entre os métodos como forma de expandir a compreensão dos fatores que influenciam a eficiência empresarial.

\section{REFERÊNCIAS BIBLIOGRÁFICAS}

ALI, Agha Iqbal; SEIFORD, Lawrence M. Translation invariance in Data Envelopment Analysis. Operations Research Letters, vol. 9, p. 403-405, 1990.

ALTMAN, Edward L. Financial rates, discriminant analysis and the prediction of corporate bankruptcy. Journal of Finance, vol. 23, n. 4, 1968.

ALTMAN, Edward L.; BAIDYA, Tara K. N.; DIAS, Luiz Manoel Ribeiro. Previsão de problemas financeiros em empresas. Revista de Administração de Empresas, vol . 19, n. 1, p. 17-28, 1979.

ANEEL - Agência Nacional de Energia Elétrica. Participação das Empresas no mercado de distribuição - Versão Preliminar - Exercício 1999. Disponível em: <http://www.aneel.gov.br/mercado/>. Acesso em: 20 nov. 2000.

BANKER, R. D.; CHARNES, A.; COOPER, W. W. Some models for estimating technical and scale inefficiencies in data enve lopment analysis. Management Science, vol. 30, n. 9, p. 1078-1092, 1984.

BELLONI, José Ângelo. Uma Metodologia de avaliação da eficiência produtiva de Universidades Federais Brasileiras. 2000a. Tese (Doutorado em Engenharia de Produção) - Departamento de Engenharia de Produção e Sistemas, Universidade Federal de Santa Catarina, Florianópolis.

BELLONI, José Ângelo. Comunicação pessoal. 2000b. E-mail enviado em 8 nov.

BOWLIN, William F. Measuring performance: an introduction to Data Envelopment Analysis. 1998. The Journal of Cost Analysis, Fall. Disponível em: <www.sceaonline.net/Journ_Fall98_BOWLIN.pdf>. Acesso em: Fev. 2002.

CERETTA, Paulo Sergio; NIEDERAUER, Carlo A. P. Rentabilidade e eficiência do setor bancário brasileiro. In: ENCONTRO ANUAL DA ASSOCIAÇÃO NACIONAL DE PÓS-GRADUAÇÃO EM ADMINISTRAÇÃO, 24., Florianópolis. Anais. Florianópolis: ANPAD, 2000.

CERETTA, Paulo Sergio \& NIEDERAUER, Carlo Alberto Pittaluga. Rentabilidade e eficiência do setor bancário brasileiro. Revista de Administração Contemporânea, v. 5, n. 3, set./dez. 2001.

CERETTA, Paulo Sergio. Investigação empírica da eficiência do setor de alimentos. Gestão $e$ Produção, v. 6, n. 3, p. 162-169, 1999.

CHARNES, Abraham; COOPER, William W.; LEWIN, Arie Y. \& SEIFORD, Lawrence. Data Envelopment Analysis: theory, methodology, and application. Massachusetts (EUA): Kluwer, 1997. 
CHARNES, Abraham; COOPER, William W.; RHODES, E. Measuring the efficiency of decision making units. European Journal of Operational Research, vol. 2, n. 6, p. 429-444, 1978. In: CHARNES, Abraham; COOPER, William W.; LEWIN, Arie Y. \& SEIFORD, Lawrence. Data Envelopment Analysis: theory, methodology, and application. Massachusetts (EUA): Kluwer, 1997.

ELIZABETSKY, Roberto. Um Modelo matemático para a decisão no banco comercial. 1976. Trabalho de Formatura - Departamento de Engenharia de Produção, Escola Politécnica, Universidade de São Paulo (Brasil): Universidade de São Paulo.

FARREL, M. J. The Measurement of productive efficiency. Journal of the Royal Statistical Society, Ser., vol. 120, p. 253-290. In: BANKER, R. D.; CHARNES, A.; COOPER, W. W. Some models for estimating technical and scale inefficiencies in data envelopment analysis. Management Science, v. 30, n. 9, p. 1078-1092, 1984.

FERNANDEZ-CASTRO, A. \& SMITH, P. Towards a general non-parametric model of corporate performance. Omega -The International Journal of Management Science, vol. 22, n. 3, p. 237-249, 1994.

FEROZ, E. H.; KIM, S.; RAAB, R. L. Financial statement analysis: a data envelopment analysis approach. Journal of the Operational Research Society, v. 54, p. 48-58, 2003.

FITZSIMMONS, James A. \& FITZSIMMONS, Mona J. Administração de serviços: operações, estratégias e tecnologia de informação. 2 ed. Porto Alegre: Bookman, 2000.

GOLANY, B.; ROLL, Y. An Application procedure for DEA. Omega - The International Journal of Management Science, vol. 17, n. 3, p. 237-250, 1998.

KANITZ, Stephen Charles.1974. Como prever falências. Exame, dez. 1974.

KANITZ, Stephen Charles. Indicadores contábeis e financeiros de previsão de insolvência: a experiência da pequena e média empresa brasileira. 1976. Tese (Livre Docência) - Faculdade de Economia, Administração e Contabilidade, Universidade de São Paulo, São Paulo.

KITTELSEN, Sverre A. C. Stepwise DEA: choosing variables for measuring technical efficiency in Norwegian electricity distribution. Memorandum no. 6/93 from Department of Economics, University of Oslo: University of Oslo, 1993.

KNOX LOVELL, C. A.; PASTOR, J. T. Units invariant and translation invariance DEA models. Operations Research Letters, vol. 18, p. 147-151.

MIGON, Marcio Nobre. Eficiência da indústria de transporte aéreo no Brasil: uma aplicação de Análise por Envoltória de Dados (DEA). Dissertação (Mestrado em Engenharia) - Universidade Federal do Rio de Janeiro: Rio de Janeiro, 2000.

NIEDERAUER, Carlos Alberto Pittaluga. Avaliação dos bolsistas de Produtividade em Pesquisa da Engenharia da Produção utilizando Data Envelopment Analysis. 1998. Dissertação (Mestrado em Engenharia de Produção) Universidade Federal de Santa Catarina, Florianópolis.

NORMAN, Michel; STOKER, Barry. Data Envelopment Analysis: the assessment of performance. Chichester: John Wiley, 1991. 
PASTOR, J. T. Translation invariance in data envelopment analysis: a generalization. Annals of Operations Research, vol. 66, p. 93-102, 1996.

RHODES, E. Data envelopment analysis and related approaches for measuring the efficiency of decision making units with an application to Program Follow Through in U.S. Public School Education. PhD Thesis. Carnegie-Mellon University, School of Urban and Public Affairs, Pittsburgh, 1978. In: BANKER, R. D.; CHARNES, A.; COOPER, W. W. Some models for estimating technical and scale inefficiencies in data envelopment analysis. Management Science, vol. 30, n. 9; p. 10781092, 1984.

SHAFER, Scott M. \& BYRD, Terry A. A Framework for measuring the efficiency of organizational investments in information technology using data envelopment analysis. Omega - International Journal of Management Science. vol. 28, p. 125-141, 1999.

SILVA, José Pereira da. Modelos para classificação de empresas com vistas a concessão de crédito. 1982. Dissertação (Mestrado) - Escola de Administração de Empresas de São Paulo, Fundação Getúlio Vargas, São Paulo. In Pereira da Silva, José. Gestão e análise de risco de crédito. São Paulo: Atlas, 1997.

SILVA, José Pereira da. Avaliação da saúde financeira das empresas. Revista de Administração de Empresas, vol. 23, n. 2, p. 41-47, 1983.

SILVA, José Pereira da. Gestão e análise de risco de crédito. São Paulo: Atlas, 1997.

SIMAK, Paul C. DEA based analysis of corporate failure. Thesis (Master of Applied Science). Graduate Department of Mechanical and Industrial Engineering, University of Toronto (Canadá): University of Toronto, 1997.

SIMAK, Paul C. Inverse and Negative DEA and their application to credit risk. Thesis (Doctor of Philosophy). Graduate Department of Mechanical and Industrial Engineering, University of Toronto (Canadá): University of Toronto, 2000.

SMITH, P. Data envelopment analysis applied to financial statements. Omega - International Journal of Management Science, vol. 18, n. 2, p. 131-138, 1990.

VALLE, Maurício Ribeiro do. O Custo de captação nos mercados americanos de Bonds $e$ internacional de Eurobonds: uma análise das maiores empresas do setor de papel \& celulose. 2000. Tese (Doutorado em Controladoria e Contabilidade) Universidade de São Paulo, São Paulo.

YUNOS, Jamaluddin Mohd \& HAWDON, David. The Efficiency of the National Electricity Board in Malaysia: an intercountry comparison using DEA. Energy Economics, vol. 19, p. 255-269, 1997.

\section{Artigo recebido em 20.10.2003. Aprovado em 28.10.2004.}




\section{Ariovaldo dos Santos}

Ariovaldo dos Santos - Silvia Pereira de Castro Casa Nova

Professor Livre Docente da FEA-USP

Interesses de pesquisa nas áreas de análise de balanços, demonstração do valor adicionado, balanço social e contabilidade inflacionária.

E-mail: arisanto@usp.br

Endereço: Av. Prof. Luciano Gualberto, 908, Cidade Universitária, São Paulo - SP, 05508-900

\section{Silvia Pereira de Castro Casa Nova,}

Professora da FEA-USP. Pós-Doutoranda da FGV-EAESP.

Interesses de pesquisa: análise de balanços, DEA, empresas de pequeno porte e pesquisa e ensino em contabilidade.

Email: silvianova@usp.br

Endereço: Av. Prof. Luciano Gualberto, 908, Cidade Universitária, São Paulo - SP, 05508-900 